Supporting Information

\title{
Metal Nanoparticles@Covalent Organic Framework@Enzymes: A Universal Platform for Fabricating Metal-enzyme Integrated
}

\author{
Nanocatalyst \\ Hao Zhao ${ }^{1}$, Guanhua Liu*1, Yunting Liu ${ }^{1}$, Xilin Liu ${ }^{1}$, Hanxi Wang ${ }^{1}$, Huaxun Chen ${ }^{1}$, \\ Jing $\mathrm{Gao}^{1}$ and Yanjun Jiang*1,2,3 \\ ${ }^{1}$ School of Chemical Engineering and Technology, Hebei University of Technology, \\ Tianjin 300130, China \\ ${ }^{2}$ State Key Laboratory of Biocatalysis and Enzyme Engineering, School of Life \\ Sciences, Hubei University, Wuhan 430062, China \\ ${ }^{3}$ National-Local Joint Engineering Laboratory for Energy Conservation in Chemical \\ Process Integration and Resources Utilization, School of Chemical Engineering and \\ Technology, Hebei University of Technology, Tianjin 300130, China \\ Corresponding author: Guanhua Liu; Yanjun Jiang \\ E-mail: ghliu@hebut.edu.cn (G. Liu); yanjunjiang@hebut.edu.cn (Y. Jiang);
}




\section{Contents}

\section{General Information}

2. Synthetic Procedures and Performance test methods

3. Supplementary Figures and Tables 


\section{General Information}

Characterization. Transmission electron microscopy (TEM) images were obtained with a Talos F200S transmission electron microscope under $200 \mathrm{kV}$ accelerating voltage. Scanning electron microscopy (SEM) images were obtained with a Nova Nano SEM450. Powder X-ray diffraction (XRD) patterns were recorded using a Bruker AXS D8 Discover X-ray diffractometer with a $\mathrm{Cu} \mathrm{K} \alpha$ anode $(\lambda=0.15406 \mathrm{~nm})$ at $40 \mathrm{kV}$ and $40 \mathrm{~mA}$. Fourier transform infrared spectra (FT-IR) were recorded with a Bruker VECTOR22 spectrometer using KBr. X-ray photoelectron spectrometry (XPS) was performed on a Thermo Scientific KAlpha X-ray photoelectron spectrometer. The nitrogen adsorption and desorption isotherms were measured using a Micromeritics ASAP 2020 analyzer. The samples were outgassed at $120{ }^{\circ} \mathrm{C}$ for $12 \mathrm{~h}$ under vacuum conditions before the test. The total pore volume of the samples was estimated from the amount adsorbed at the highest $\mathrm{P} / \mathrm{P}_{0}$ (ca. 0.99) by the Barrett-Joyner-Halenda (BJH) model. Thermogravimetric analysis (TGA) was carried out on TA Instrments-water LLC instrument over the temperature range of 30 to $800{ }^{\circ} \mathrm{C}$ under $\mathrm{N}_{2}$ atmosphere with a heating rate of $10{ }^{\circ} \mathrm{C} \mathrm{min}^{-1}$.

\section{Synthetic Procedures and Performance test methods}

Preparation of TTB-DHBD. The preparation method of TTB-DHBD is similar to that of Tz-Da. Firstly, 2,4,6-Tris(4-formylphenyl)-1,3,5-triazine (98.34 mg), 3,3'dihydroxybenzidine $(36.04 \mathrm{mg})$, mesitylene $(5.1 \mathrm{~mL}), 1,4$-dioxane $(0.9 \mathrm{~mL})$ and acetic acid $(6 \mathrm{M}, 0.6 \mathrm{~mL})$ were added to the reaction tube with side tube and sonicated for 15 minutes to make the mixture fully dispersed. Then, the mixture was reacted in an oil bath at $120{ }^{\circ} \mathrm{C}$ for 3 days. When the reaction was completed, the resulting precipitate was first washed with dioxane three times, then washed with N,N-dimethylacetamide until there was no turbidity. Finally, it was washed with absolute ethanol, and the resulting product was vacuum dried at $120{ }^{\circ} \mathrm{C}$ for 12 hours.

Hydrolysis activity of free OPH and Pd@COF@OPH. Colorimetric method was used to detect the hydrolysis activity of free $\mathrm{OPH}$ with methyl parathion as substrate. Specifically, free OPH (50 $\mu \mathrm{L}, 1 \mathrm{mg} / \mathrm{mL})$ and Tris- $\mathrm{HCl}(1.94 \mathrm{~mL}, 50 \mathrm{mM}, \mathrm{pH} 9.0)$ were mixed, and then methyl parathion ( $10 \mu \mathrm{L}, 38 \mu \mathrm{mol} / \mathrm{mL}$ in acetonitrile) was added and 
reacted for $1 \mathrm{~min}$ at $40{ }^{\circ} \mathrm{C}$. The resulting yellow solution was detected with an ultraviolet spectrophotometer at a wavelength of $410 \mathrm{~nm}$. One unit is defined as the amount of enzyme required to produce $1 \mu \mathrm{mol} 4-\mathrm{NP}$ per minute.

The hydrolysis activity of Pd@COF@OPH was measured by a method similar to that of free OPH. Specifically, Pd@COF@OPH (5 mg) and Tris-HCl (0.962 mL, 50 $\mathrm{mM}, \mathrm{pH} 9.0)$ were mixed, and then methyl parathion $(38 \mu \mathrm{L}, 38 \mu \mathrm{mol} / \mathrm{mL}$ in acetonitrile) was added and reacted for $1 \mathrm{~min}$ at $40^{\circ} \mathrm{C}$. The resulting yellow solution was detected with an ultraviolet spectrophotometer at a wavelength of $410 \mathrm{~nm}$.

The stability of free OPH and Pd@Tz-Da@OPH. The pH stability was determined by putting free $\mathrm{OPH}$ and $\mathrm{Pd} @ \mathrm{Tz}-\mathrm{Da} @ \mathrm{OPH}$ into buffer solutions of pH=4 and $\mathrm{pH}=10$ and incubating for different times at room temperature. Then, the $\mathrm{pH}$ stability was evaluated by measuring the remaining activity of the enzyme after the incubation.

The thermal stability was determined by putting free OPH and Pd@Tz-Da@OPH into Tris- $\mathrm{HCl}$ buffer solution $(\mathrm{pH}=9,50 \mathrm{mM})$ at $50^{\circ} \mathrm{C}$ and $70^{\circ} \mathrm{C}$, and incubating for a period of time. Then, the thermal stability was evaluated by measuring the remaining activity of the enzyme after the incubation.

The storage stability of OPH under different conditions was determined. The specific operation is to store the free OPH in PBS $(\mathrm{pH}=7,100 \mathrm{mM})$ and Pd NPs solution $(0.5$ mg/mL),Pd@Tz-Da@OPH in PBS (pH=7, 100 mM), and measure the hydrolytic activity of OPH at regular intervals. The untreated hydrolysis activity is defined as $100 \%$

Cascade degradation of organophosphate nerve agents by Pd@Tz-Da@OPH. Pd@Tz-Da@OPH was used as a catalyst for the cascade degradation of organophosphate nerve agents. Methyl parathion was used as a substrate to investigate the effects of temperature, $\mathrm{pH}$ value of the solution and concentration of $\mathrm{NaBH}_{4}$ on the cascade degradation activity of $\mathrm{Pd} @ \mathrm{Tz}-\mathrm{Da} @ \mathrm{OPH}$. Firstly, the pH value of the solution was optimized under the conditions of substrate concentration of $0.96 \mu \mathrm{mol} / \mathrm{mL}$, temperature of $50{ }^{\circ} \mathrm{C}$ and $\mathrm{NaBH}_{4}$ concentration of $15 \mathrm{mg} / \mathrm{mL}$. Then, the temperature was optimized under the conditions of substrate concentration $0.96 \mu \mathrm{mol} / \mathrm{mL}, \mathrm{pH}=9$ 
and $\mathrm{NaBH}_{4}$ concentration $15 \mathrm{mg} / \mathrm{mL}$. Finally, the concentration of $\mathrm{NaBH}_{4}$ was optimized under the conditions of substrate concentration of $0.96 \mu \mathrm{mol} / \mathrm{mL}, \mathrm{pH}$ of 9 and temperature of $70^{\circ} \mathrm{C}$.

The reusability of Pd@Tz-Da@OPH was evaluated by studying Pd@Tz-Da@OPH in the repeated cascade degradation of methyl parathion. Specifically, $\mathrm{NaBH}_{4}(18.75$ mg) and methyl parathion ( $38 \mu \mathrm{L}, 38 \mu \mathrm{mol} / \mathrm{mL}$ ) were added to the Tris-HCl buffer solution $(1.46$ mL, pH=9, 50 mM) containing 5 mg of Pd@Tz-Da@OPH and reacted at $70^{\circ} \mathrm{C}$ for 50 minutes. Then, the cascade degradation efficiency was obtained by measuring the amount of 4-AP in the solution after the reaction. After each reaction is completed, the catalyst was cleaned with Tris- $\mathrm{HCl}$ buffer solution and then the next cycle is performed.

Degradation of 4-NP by Pd@Tz-Da and Pd@Tz-Da@OPH.Pd@Tz-Da or Pd@Tz-Da@OPH was used as a catalyst for degradation of 4-NP. Specifically, catalyst (0.0775 mg, same content of Pd), $\mathrm{NaBH}_{4}(18.75 \mathrm{mg})$ and 4-NP $(1.5 \mathrm{~mL}, 0.96 \mu \mathrm{mol} / \mathrm{mL})$ were added to the centrifuge tube and reacted at $70^{\circ} \mathrm{C}$ for $1 \mathrm{~min}$. Then, the degradation activity was obtained by measuring the amount of residual 4-NP in the solution after the reaction.

\section{Cascade degradation of organophosphate nerve agents by Pd@TTB-} DHBD@OPH.Pd@Tz-Da@OPH was used as a catalyst for the cascade degradation of organophosphate nerve agents. Specifically, $\mathrm{NaBH}_{4}(18.75 \mathrm{mg})$ and methyl parathion ( $38 \mu \mathrm{L}, 38 \mu \mathrm{mol} / \mathrm{mL})$ were added to the Tris- $\mathrm{HCl}$ buffer solution $(1.46 \mathrm{~mL}$, $\mathrm{pH}=9,50 \mathrm{mM}$ ) containing $5 \mathrm{mg}$ of Pd@TTB-DHBD@OPH and reacted at $70{ }^{\circ} \mathrm{C}$ for 50 minutes. Then, the cascade degradation situation was obtained by measuring the amount of 4-AP in the solution after the reaction.

Phenol detection by Pt@Tz-Da@GOx. To demonstrate the versatility of the COFbased integrated nanocatalyst preparation strategy, Pt nanoparticles and glucose oxidase were immobilized in Tz-Da COF for obtainingPt@Tz-Da@GOx. And the Pt@Tz-Da@GOx was used for colorimetric detection of phenol: different concentrations of phenol solution $(0.32 \mathrm{~mL}, 12.5-12000 \mu \mathrm{M})$, glucose solution $(0.08$ $\mathrm{mL}, 0.5 \mathrm{M})$ and 4-aminoantipyrine solution $(0.8 \mathrm{~mL}, 0.0125 \mathrm{M})$ were mixed. Then 0.5 
mL of Pt@Tz-Da@GOx solution (10 mg/mL) was added and reacted for 60 minutes at $25{ }^{\circ} \mathrm{C}$. After the reaction, the catalyst was filtered and removed, and the solution was detected by UV-Vis spectrophotometer at $505 \mathrm{~nm}$ wavelength. All the above solutions were prepared by PBS (100 mM, pH=8). 


\section{Supplementary Figures and Tables}

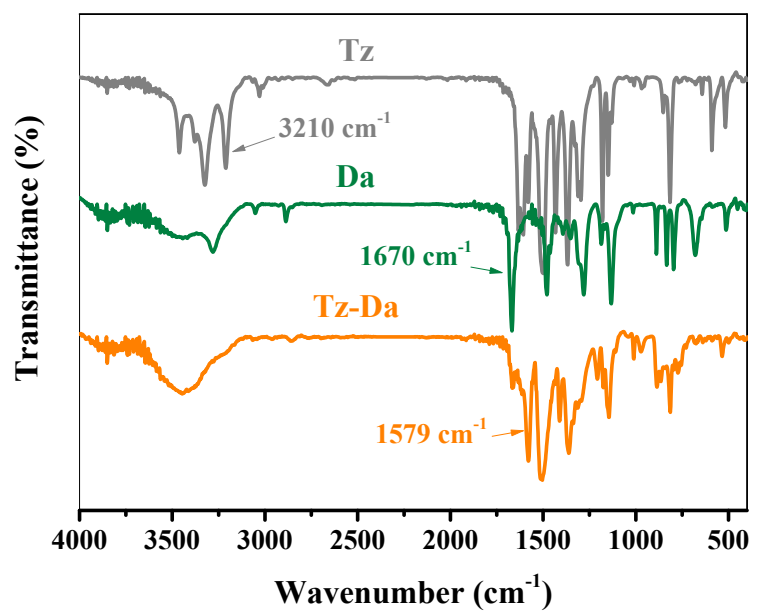

Figure S1 FT-IR spectra of Tz, Da and Tz-Da. 


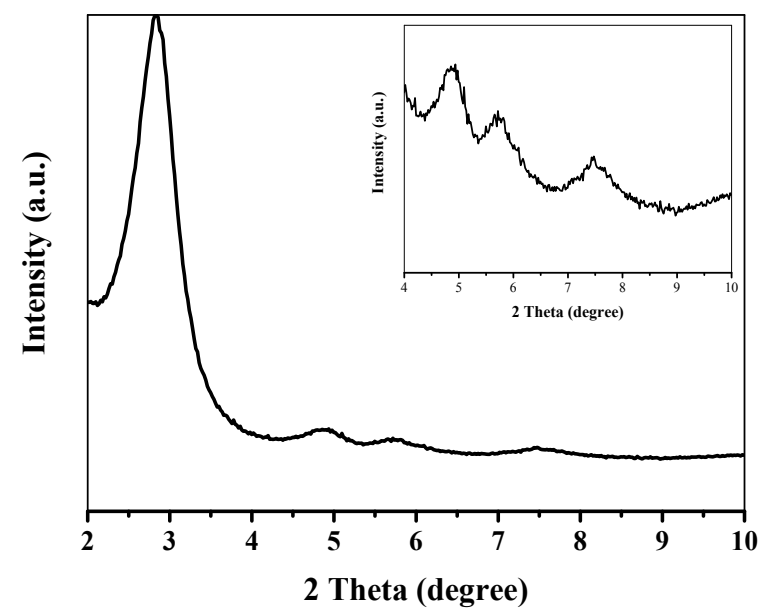

Figure S2 Small-angle PXRD pattern of Tz-Da. 


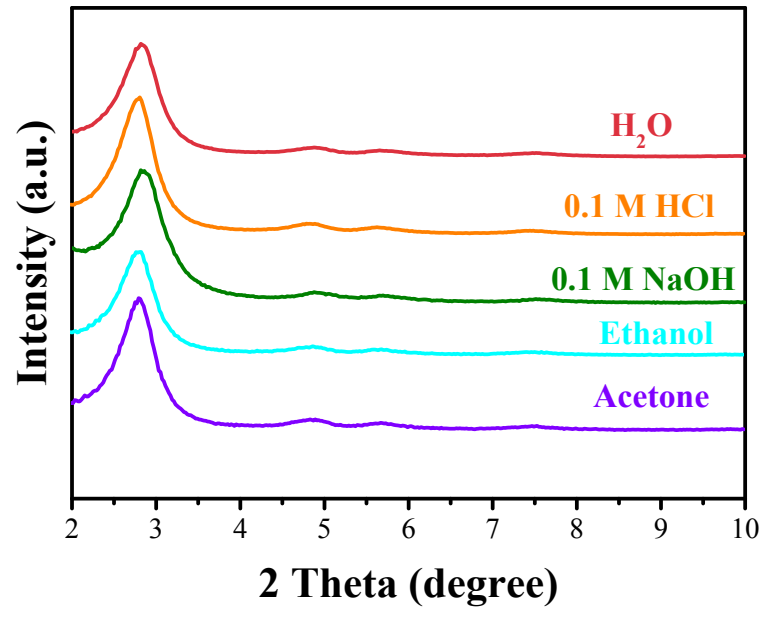

Figure S3 Small-angle PXRD patterns of Tz-Da after immersing in $\mathrm{H}_{2} \mathrm{O}, \mathrm{HCl}(0.1$ $\mathrm{M}), \mathrm{NaOH}(0.1 \mathrm{M})$, ethanol, acetone solvents. 


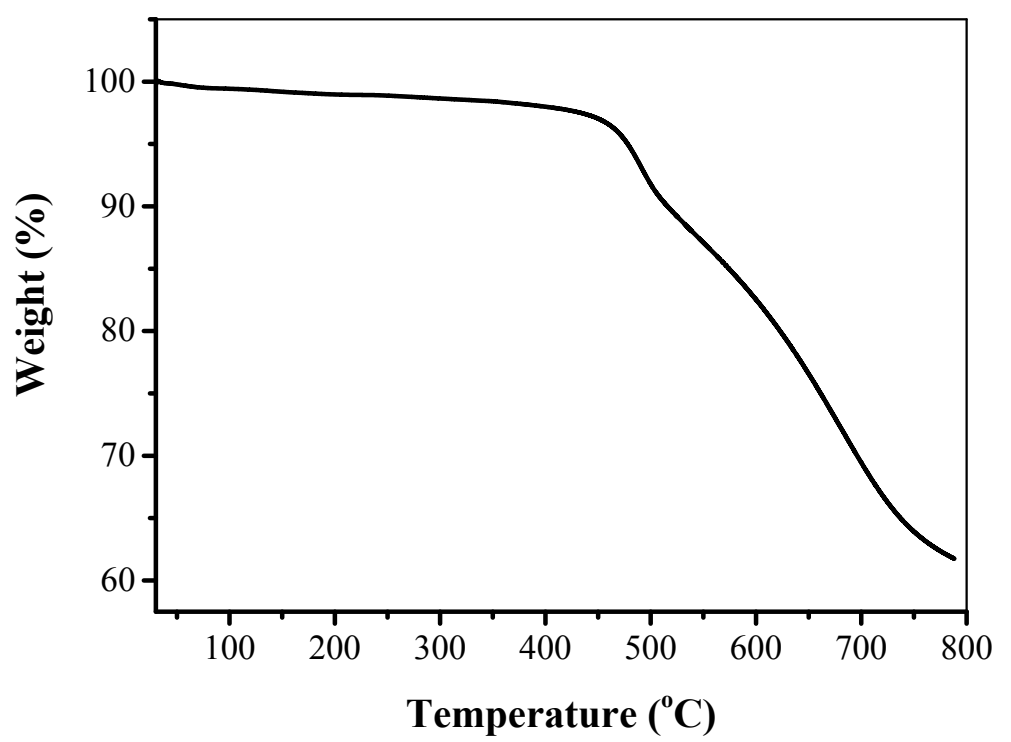

Figure S4 TGA curve of TzDa. 


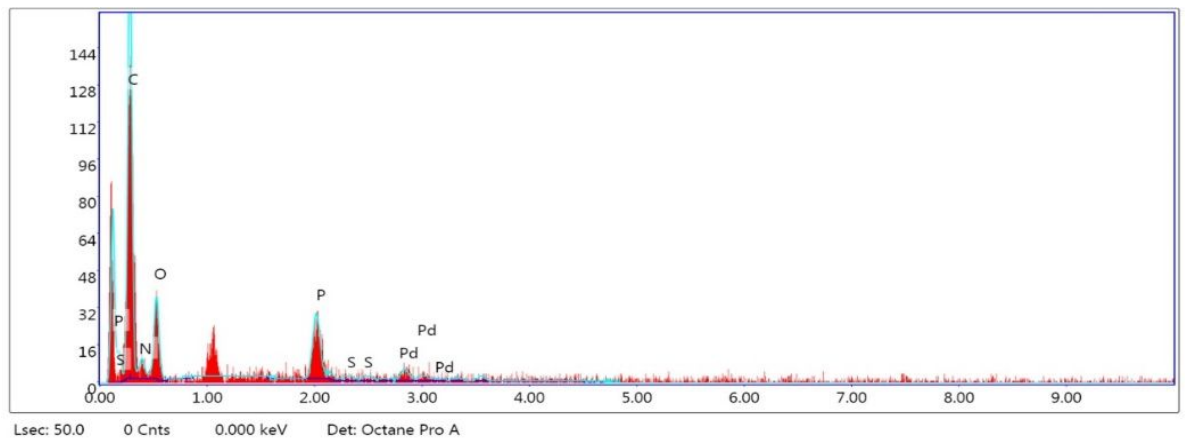

Figure S5 EDX of Pd@Tz-Da@OPH. 


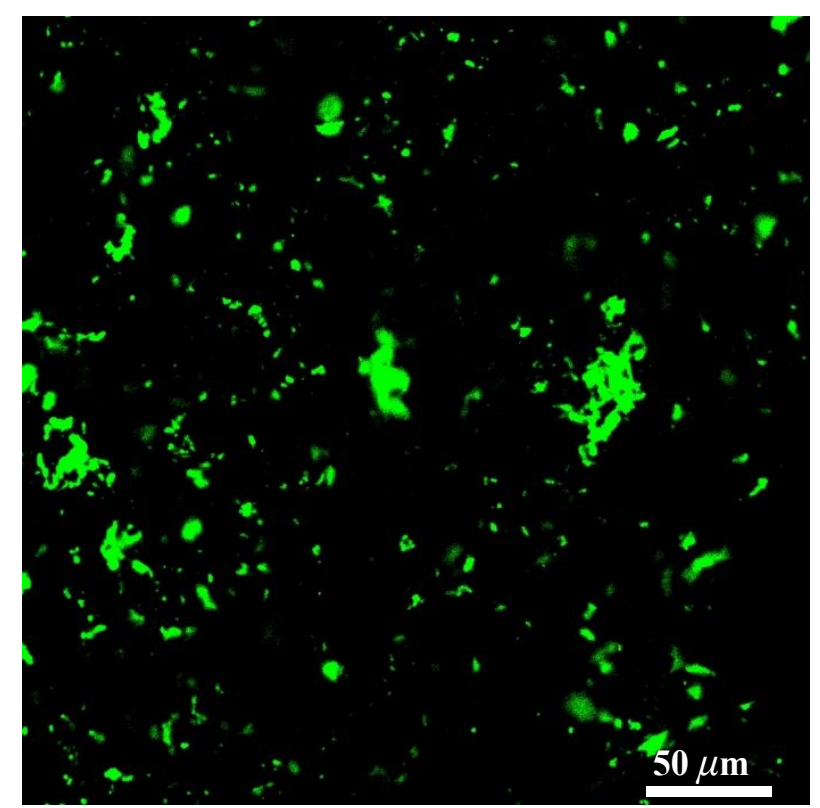

Figure S6 CLSM image of the Pd@Tz-Da@FITC-OPH 


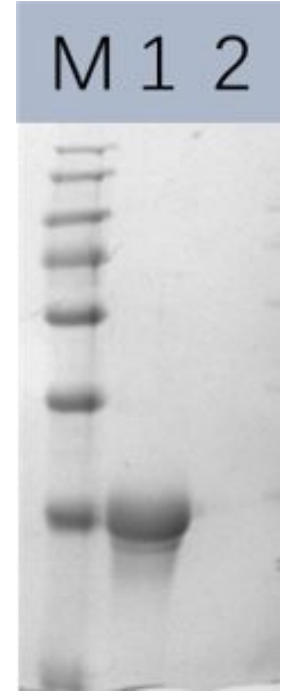

Figure S7 SDS-PAGE gel (M: protein marker, lane 1: free OPH and lane 2: washed Pd@Tz-Da@OPH). 


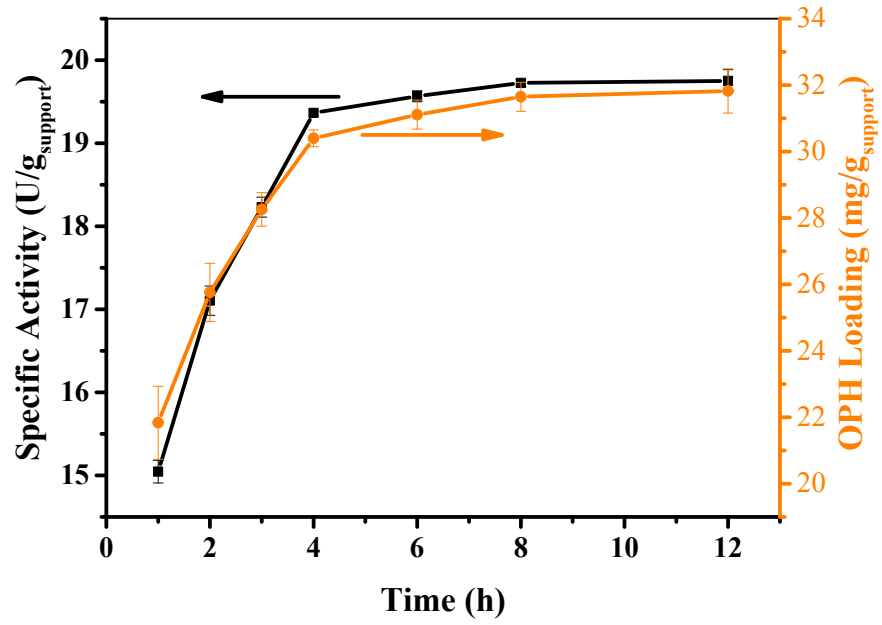

Figure S8 Effect of OPH loading (saffron) and specific activity (black) of Pd@TzDa@OPH with immobilization time. 


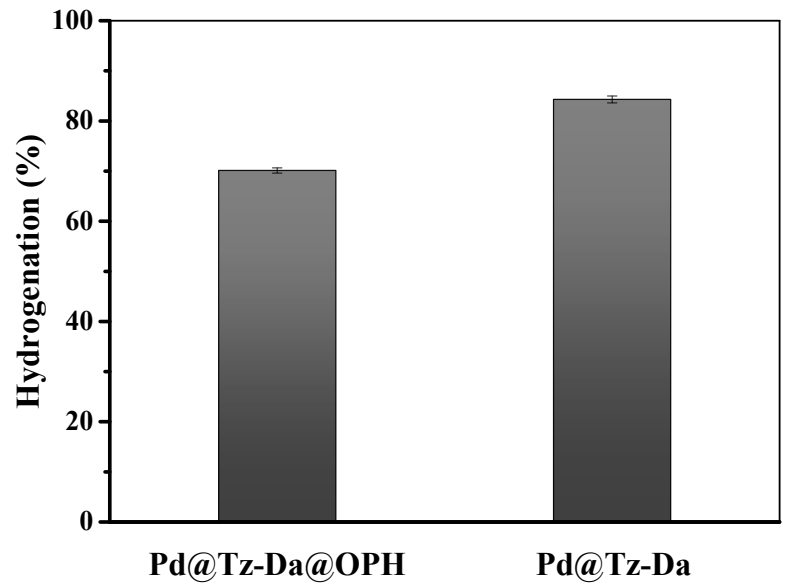

Figure S9 Ability of Pd@Tz-Da and Pd@Tz-Da@OPH to convert 4-NP to 4-AP. 

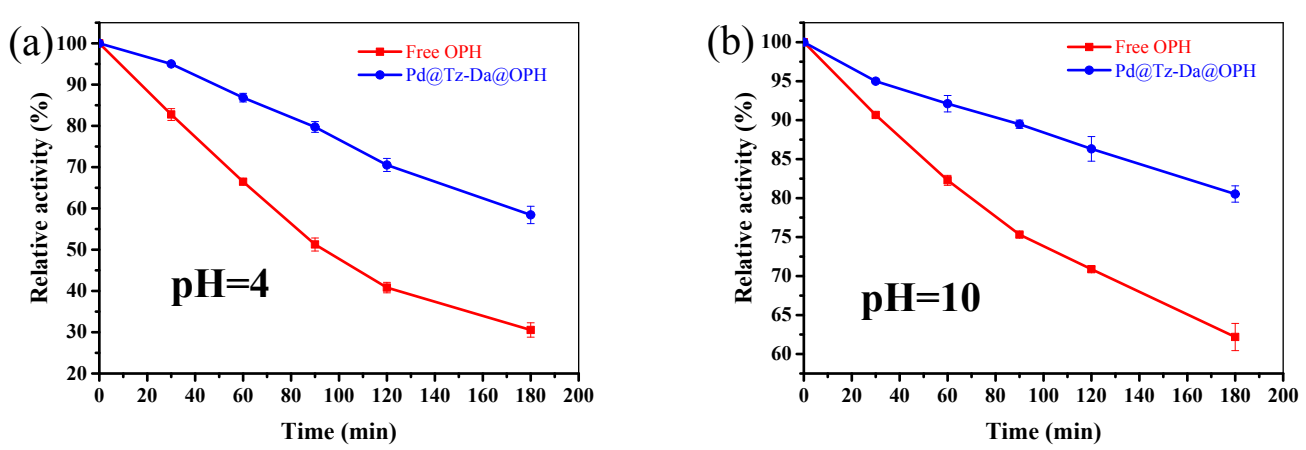

Figure S10 Relative enzyme activity of free and immobilized OPH after being treated at $\mathrm{pH}=4$ and $\mathrm{pH}=10$ with different time. 

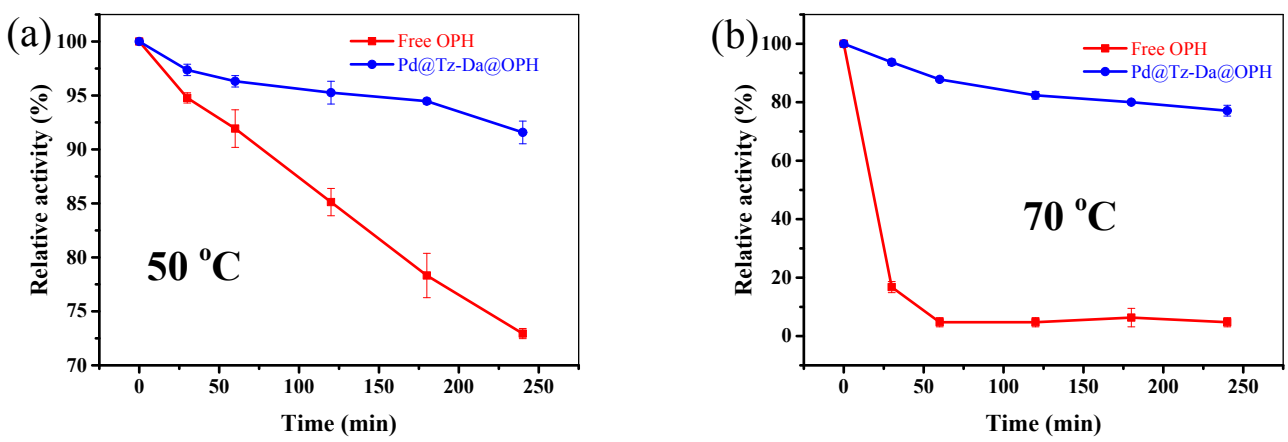

Figure S11 Relative enzyme activity of free and immobilized OPH after being treated at $50^{\circ} \mathrm{C}$ and $70{ }^{\circ} \mathrm{C}$ with different time. 
(a)

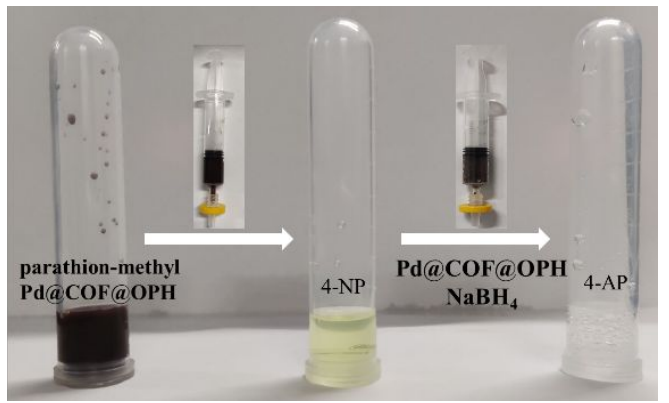

(b)

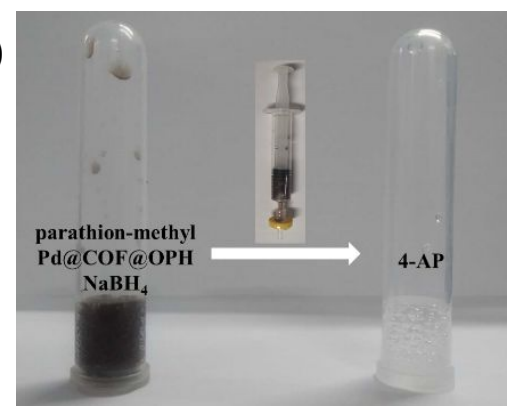

Figure S12 Photographic images of two-step (a) and one-pot (b) degradation of methyl parathion with Pd@Tz-Da@OPH 

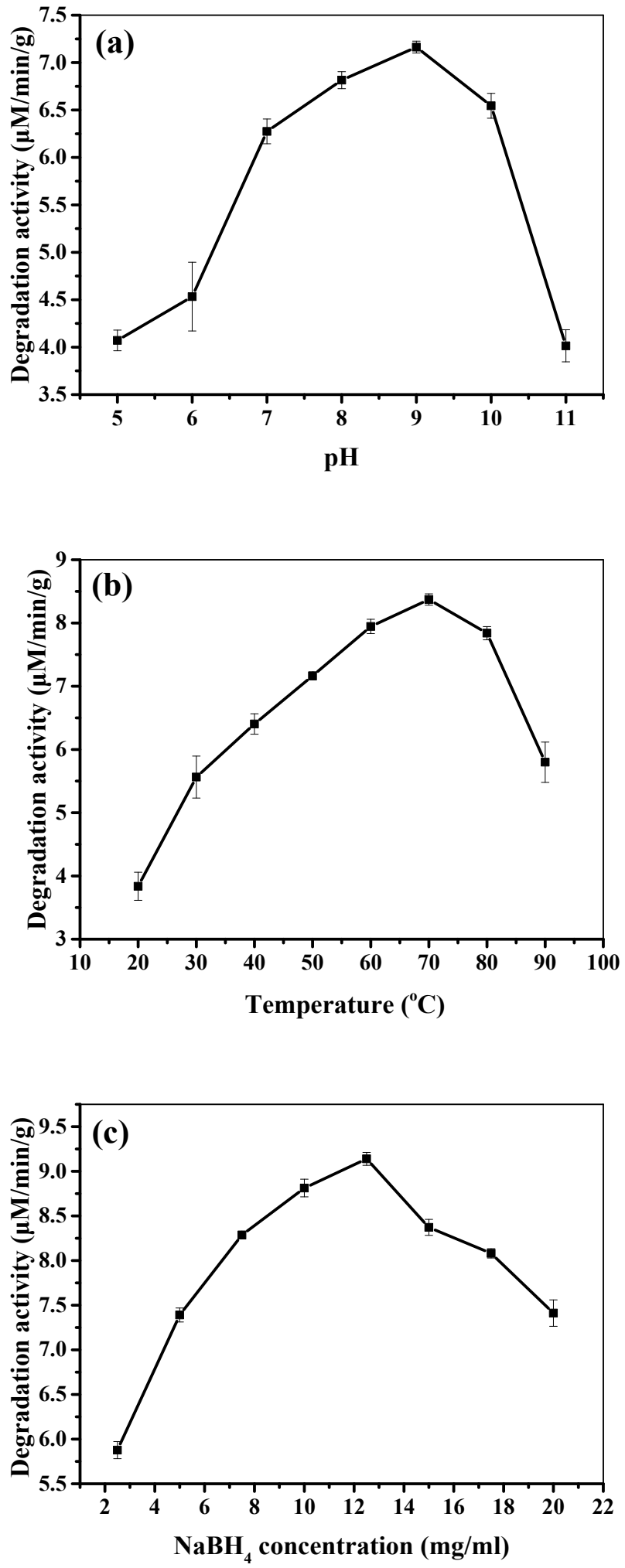

Figure S13 The catalytic activity of Pd@Tz-Da@OPH under different conditions of $\mathrm{pH}$ value (a), temperature (b) and $\mathrm{NaBH}_{4}$ concentration (c). 


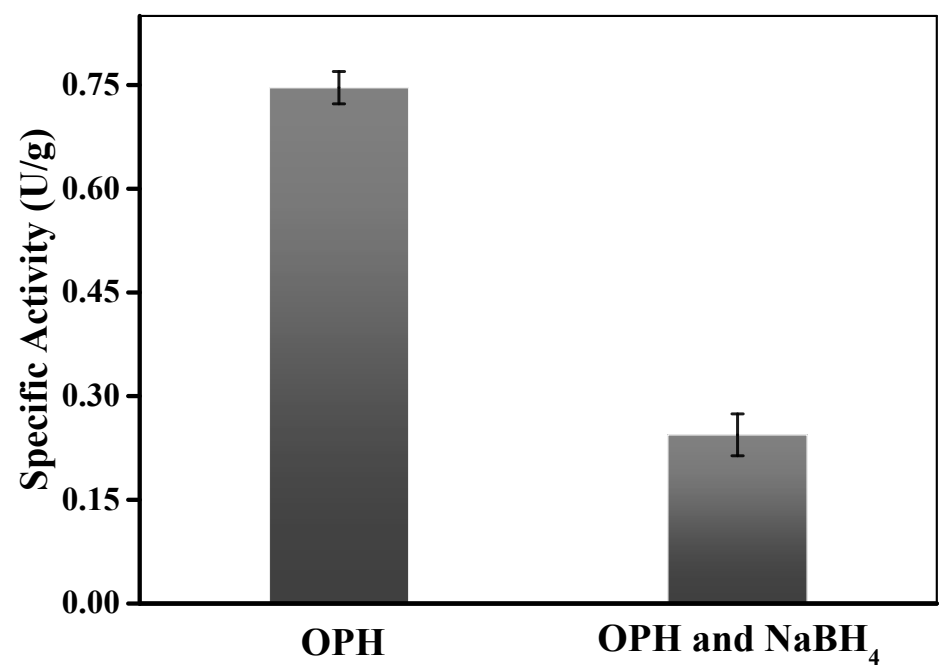

Figure S14 Effect of $\mathrm{NaBH}_{4}$ on $\mathrm{OPH}$ hydrolase activity 


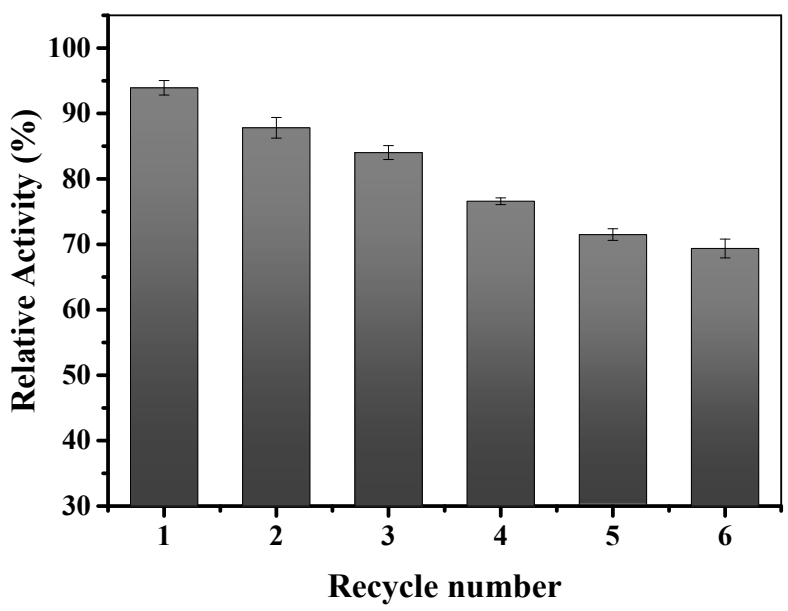

Figure S15 The relative activity of OPH after multiple degradation cycles. 

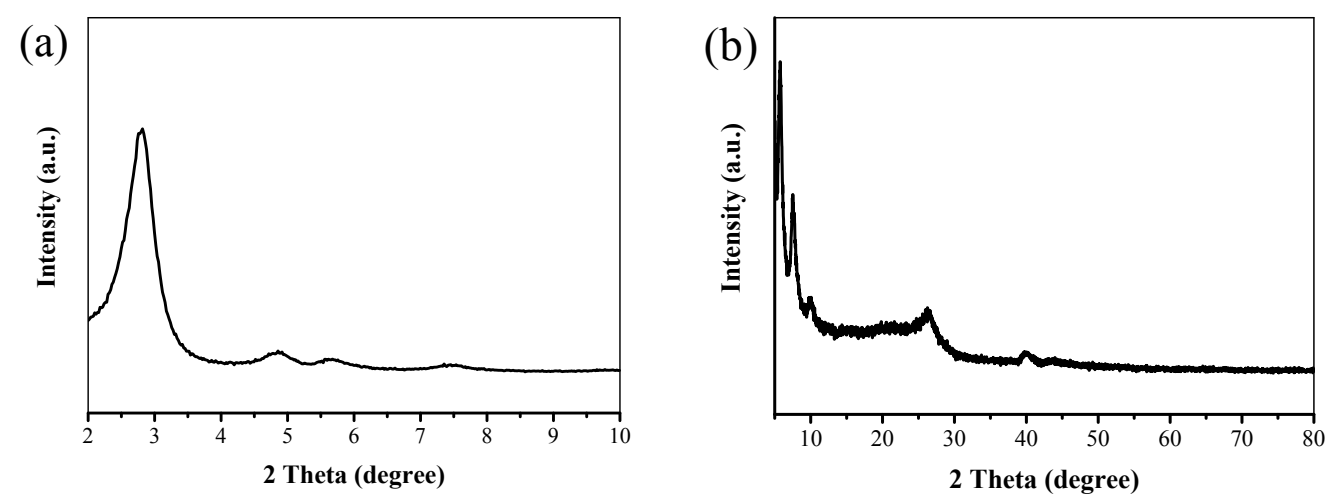

Figure S16 Small-angle and wide-angle PXRD patterns of Pd@Tz-Da@OPH after 6 times of cascade reaction. 

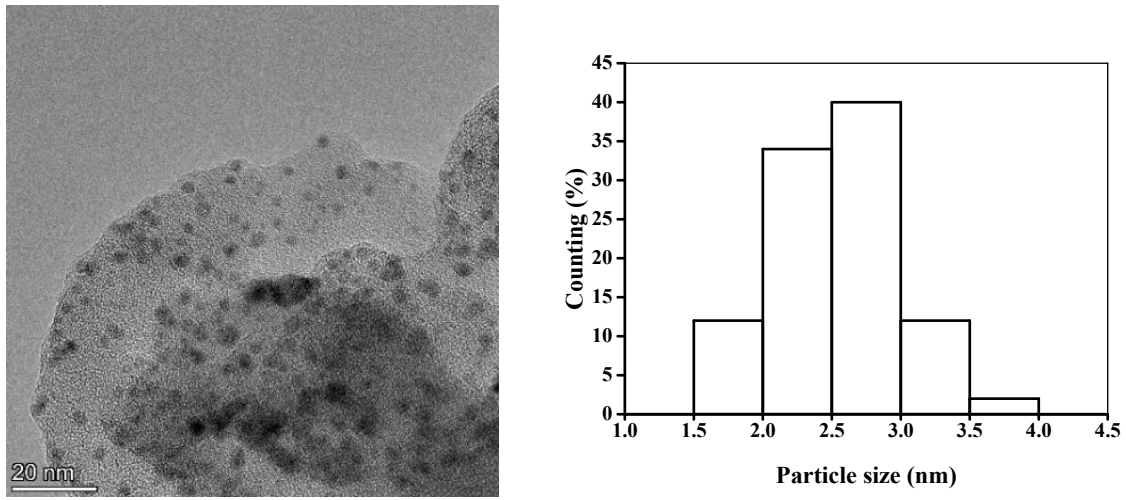

Figure S17 TEM of Pd@Tz-Da@OPH and the size distribution of Pd NPs after 6 times of cascade reaction. 


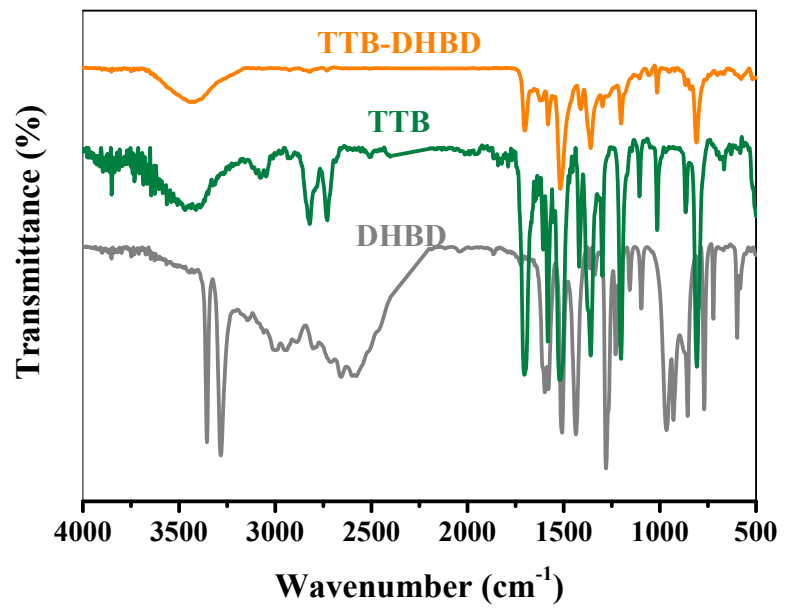

Figure S18 FT-IR spectra of DHBD, TTB and TTB-DHBD. 


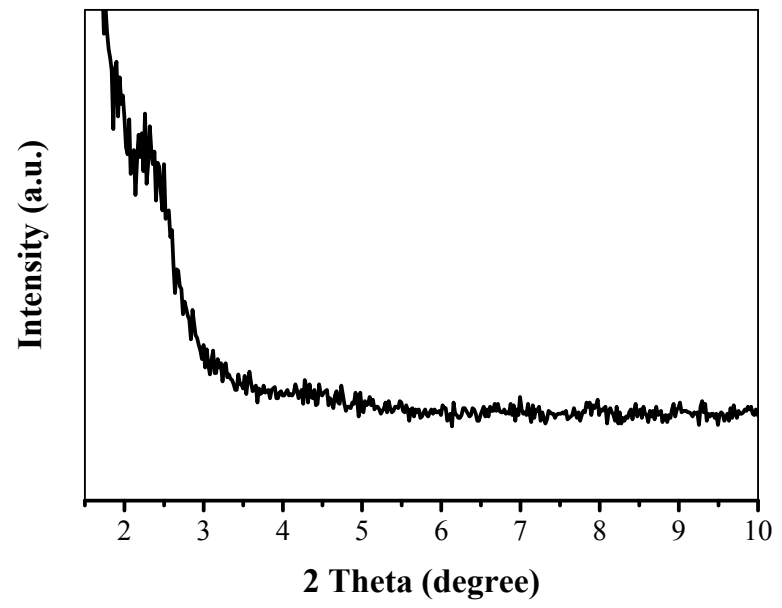

Figure S19 Small-angle PXRD pattern of TTB-DHBD. 


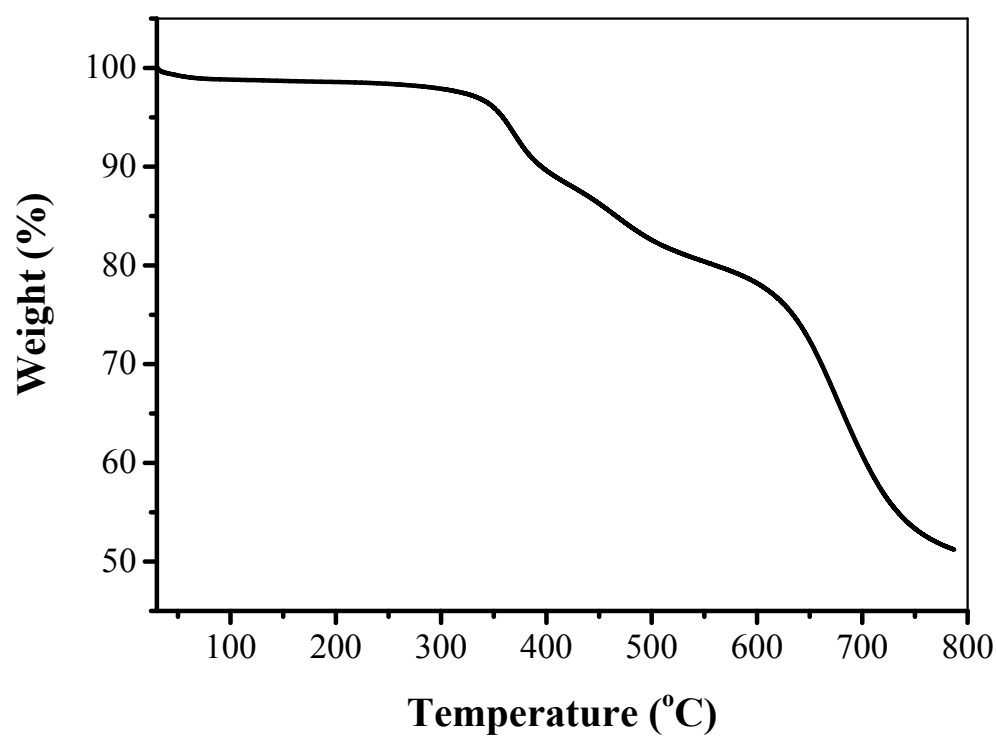

Figure S20 TGA curve of TTB-DHBD. 

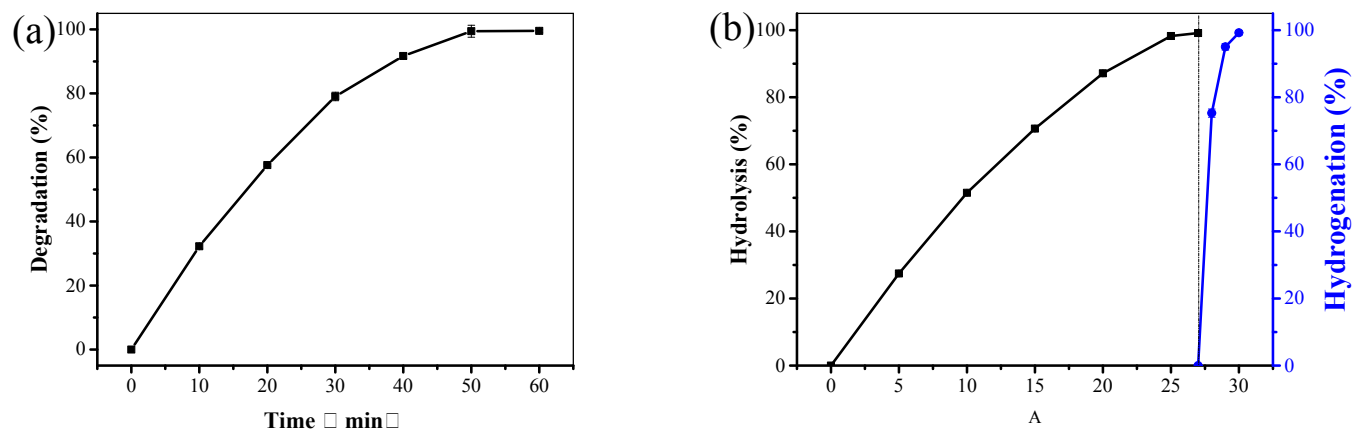

Figure S21 Degradation profiles of parathion-methyl that degraded by Pd@TTB-

DHBD@OPH (a) and cascade degradation process $\mathrm{NaBH}_{4}$ was added after the hydrolytic step (b). 


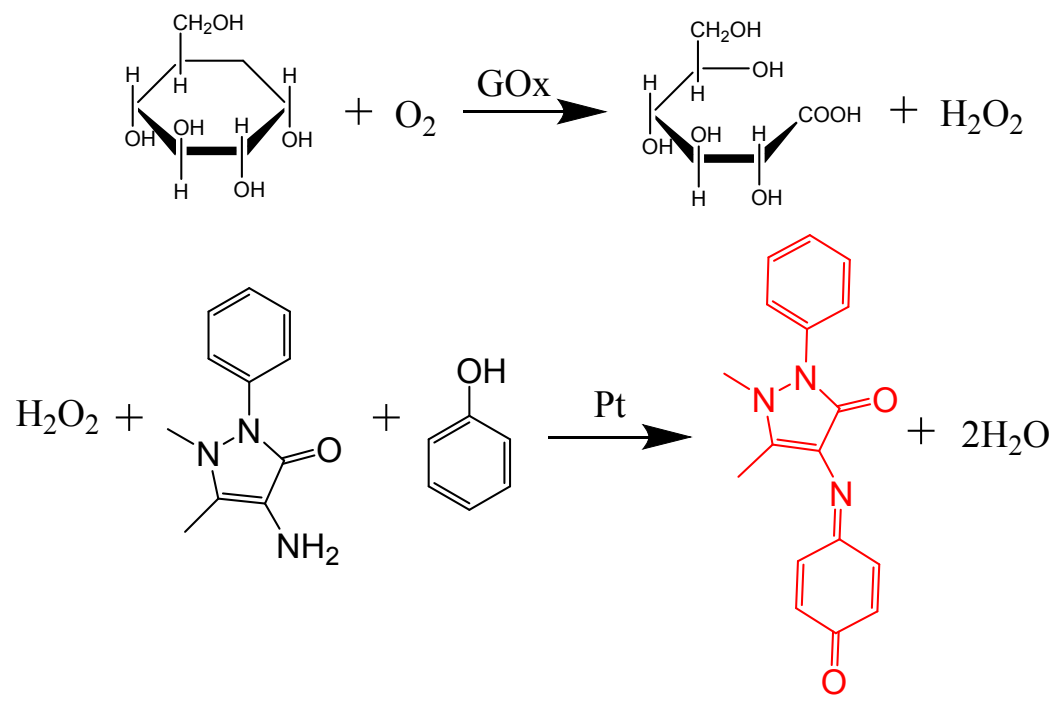

Figure S22 Schematic diagram of phenol detection. 
Table S1 Atomic and weight percentages of Pd@Tz-Da@OPH.

\begin{tabular}{ccccccc}
\hline Element & C K & N K & O K & P K & S K & Pd K \\
\hline Atomic (\%) & 70.95 & 8.28 & 17.48 & 2.84 & 0.15 & 0.29 \\
Weight (\%) & 62.11 & 8.46 & 20.40 & 6.42 & 0.35 & 2.25 \\
\hline
\end{tabular}

SEM-EDX is often used as an accessory of electron microscope for component analysis or semiquantitative analysis, which is not as accurate as ICP for metal characterization. In this study, palladium content was determined by ICP. 
Table S2 BET surface area and average pore diameter of Tz-Da, Pd@Tz-Da and Pd@Tz-Da@OPH

\begin{tabular}{ccc}
\hline & $\begin{array}{c}\text { BET Surface Area } \\
\left(\mathbf{m}^{2} / \mathbf{g}\right)\end{array}$ & $\begin{array}{c}\text { Average Pore Diameter } \\
(\mathbf{n m})\end{array}$ \\
\hline Tz-Da & 2125 & 3.05 \\
$\mathrm{Pd} @ \mathrm{Tz}-\mathrm{Da}$ & 920 & 2.78 \\
$\mathrm{Pd} @ \mathrm{Tz}-\mathrm{Da} @ \mathrm{OPH}$ & 549 & 2.51 \\
\hline
\end{tabular}


Table S3 Comparison of this work with other papers for the detection of phenol.

\begin{tabular}{cccc}
\hline Sensor & $\begin{array}{c}\text { Linear range for } \\
\text { phenol }\end{array}$ & LOD & Reference \\
\hline Pt@Tz-Da@GOx & $\begin{array}{c}12.5-300 \mu \mathrm{M} \\
300-1200 \mu \mathrm{M}\end{array}$ & $2.48 \mu \mathrm{M}$ & This work \\
HRP@ZIF-8-GOx & $0-100 \mu \mathrm{M}$ & $0.86 \mu \mathrm{M}$ & 1 \\
ZIF-8@BHb & $0-200 \mu \mathrm{M}$ & $0.1 \mu \mathrm{M}$ & 2 \\
$\mathrm{MoS}_{2}-\mathrm{Pt}_{3} \mathrm{Au}_{1}$ & $4-1000 \mu \mathrm{M}$ & $0.2 \mu \mathrm{M}$ & 3 \\
$\mathrm{Fe}_{3} \mathrm{O}_{4} / \mathrm{rGO} / \mathrm{MOF}$ & $10-80 \mu \mathrm{M}$ & $3.33 \mu \mathrm{M}$ & 4 \\
HRP@ZIF-8 & $0.5-100 \mu \mathrm{M}$. & $0.5 \mu \mathrm{M}$ & 5 \\
HRP-inorganic hybrid & $0-100 \mu \mathrm{M}$ & $1.0 \mu \mathrm{M}$ & 6 \\
nanoflowers & &
\end{tabular}

LOD: low limit of detection. 


\section{REFERENCES}

(1) Liu, H.; Du, Y.; Gao, J.; Zhou, L.; He, Y.; Ma, L.; Liu, G.; Huang, Z.; Jiang, Y. Compartmentalization of Biocatalysts by Immobilizing Bienzyme in Hollow ZIF-8 for Colorimetric Detection of Glucose and Phenol. Ind. Eng. Chem. Res. 2019, 59, 42-51. (2) Yin, Y.; Gao, C.; Xiao, Q.; Lin, G.; Lin, Z.; Cai, Z.; Yang, H. Protein-Metal Organic Framework Hybrid Composites with Intrinsic Peroxidase-like Activity as a Colorimetric Biosensing Platform. ACS Appl. Mater. Interfaces 2016, 8, 29052-29061. (3) Cai, S.; Han, Q.; Qi, C.; Wang, X.; Wang, T.; Jia, X.; Yang, R.; Wang, C. $\mathrm{MoS}_{2^{-}}$ $\mathrm{Pt}_{3} \mathrm{Au}_{1}$ Nanocomposites with Enhanced Peroxidase-Like Activities for Selective Colorimetric Detection of Phenol. Chin. J. Chem. 2017, 35, 605-612.

(4) Wang, Y.; Zhao, M.; Hou, C.; Yang, X.; Li, Z.; Meng, Q.; Liang, C. Graphenebased magnetic metal organic framework nanocomposite for sensitive colorimetric detection and facile degradation of phenol. J. Taiwan Inst. Chem. Eng. 2019, 102, 312320.

(5) Wang, L.; Zhi, W.; Lian, D.; Wang, Y.; Han, J.; Wang, Y. HRP@ZIF-8/DNA Hybrids: Functionality Integration of ZIF-8 via Biomineralization and Surface Absorption. ACS Sustainable Chemistry \& Engineering 2019, 7, 14611-14620.

(6) Lin, Z.; Xiao, Y.; Yin, Y.; Hu, W.; Liu, W.; Yang, H. Facile synthesis of enzymeinorganic hybrid nanoflowers and its application as a colorimetric platform for visual detection of hydrogen peroxide and phenol. ACS Appl. Mater. Interfaces 2014, 6, 10775-82. 